\title{
Immersive virtual reality effects on balance and cognition in Parkinson's disease
}

1, 2 Oliveira, AA; 2Jaen, M; ${ }^{2}$ Peixoto, D; Machado, A.

${ }^{1}$ Graduate Course in Rehabilitation Sciences, ${ }^{2}$ Graduate Course in Psychology and Health

\section{INTRODUCTION}

Parkinson's disease is a neurodegenerative disorder that disrupt the patients postural control and mobility. In addition to the typically characterized motor symptoms (bradykinesia, rigidity and resting tremor), it also manifests cognitive disturbances. The current therapeutic approach has been a combination of pharmaco and physiotherapy at a regular basis. Immersive virtual reality (IVR) can be added as a perceptual neurocognitive tool with technological rehabilitating value.

\section{OBJECTIVE}

The aim of this study was to evaluate the effects of a training protocol using IVR as strategy to rehabilitate the balance, motor coordination, gait and cognition in Parkinson's disease.

\section{METHOD}

Twenty-three participants under the standard neurological attendance at the neurology hospital section were randomly set into three groups: Experimental group $(n=11)$ exposed to an IVR environment in which the patients had to walk on a virtual "tight rope"; Lecture group ( $n=6)$ exposed to lecture sessions about falls avoidance and physical improvement; Control group $(n=6)$ received the regular neurologist's attendance in which all participants also attended. In pre and post training assessment were used Hoehn \& Yahr scale (HYS), Berg Balance Scale (BBS), Timed Up and Go Test (TUG), 10 meter Walk test (10WT), Unified Parkinson's Disease Rating Scale III (UPDRS III) to balance and gait. Mini-Mental State Examination (MMSE), State-Trait Anxiety Inventory (STAI) and the Rivermead Behavioral Memory Test (RBMT) to assess the cognitive status. The intervention took 5 weeks, twice a week, 1 hour/session. No secondary symptoms were observed. The study was performed at the University's Laboratory of Virtual Reality

\section{RESULTS}

Cognitive and physical effects were assessed in two time points at the initial day and after the classes. Cognitive effects: There were no significant differences between the groups (Table 1).

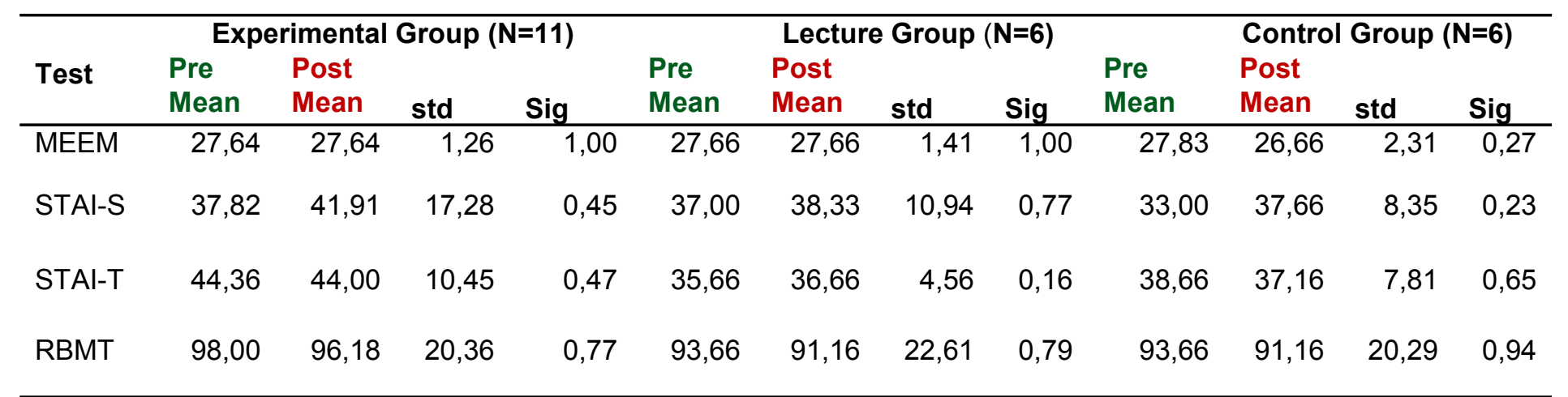

Physical effects: there was a significant difference between the experimental group and the other training groups in the 10WT and the UPDRS III (Table 2).

\begin{tabular}{|c|c|c|c|c|c|c|c|c|c|c|c|c|}
\hline \multirow{3}{*}{ Test } & \multicolumn{4}{|c|}{ Experimental Group $(\mathrm{N}=11)$} & \multicolumn{5}{|c|}{ Lecture Group $(\mathrm{N}=6)$} & \multirow{2}{*}{\multicolumn{3}{|c|}{$\begin{array}{l}\text { Control Group ( } \mathrm{N}=6 \text { ) } \\
\text { Post }\end{array}$}} \\
\hline & & Post & & & $\begin{array}{l}\text { Pre } \\
\text { Meanc }\end{array}$ & & & & $\begin{array}{l}\text { Pre } \\
M o n\end{array}$ & & & \\
\hline & $\begin{array}{l}\text { Means } \\
54,27\end{array}$ & $\begin{array}{l}\text { Means } \\
5127\end{array}$ & std & Sig & Means & $\begin{array}{l}\text { Means } \\
5250\end{array}$ & std & Sig & Means & $\begin{array}{l}\text { Means } \\
5300\end{array}$ & 20 & \\
\hline & & & & & & & & & & & & \\
\hline TUG & 8,81 & 9,14 & 1,60 & 0,50 & 9,68 & 9,83 & 1,20 & 0,78 & 10,80 & 11,80 & 1,45 & 0,15 \\
\hline 10WT & 15,06 & 12,61 & 1,42 & $0,07^{*}$ & 19,83 & 20,03 & 4,42 & 0,91 & 15,75 & 16,03 & 1,56 & 0,67 \\
\hline Cadence & 115,82 & 113,00 & 5,09 & 0,90 & 115,16 & 120,66 & 12,07 & 0,31 & 110,16 & 109,50 & 5,60 & 0,78 \\
\hline Speed & 1,25 & 1,35 & 0,21 & 0,16 & 1,04 & 1,24 & 0,25 & 0,11 & 1,09 & 1,12 & 0,15 & 0,58 \\
\hline UPDRS III & 22,18 & 19,45 & 1,19 & $0,01^{*}$ & 22,00 & 20,33 & 2,06 & 0,10 & 20,33 & 21,16 & 2,13 & 0,38 \\
\hline
\end{tabular}

\begin{tabular}{|c|c|c|c|c|c|}
\hline & $\begin{array}{l}\text { Experimental } \\
\text { Group }\end{array}$ & $\begin{array}{l}\text { Lecture } \\
\text { Group }\end{array}$ & $\begin{array}{l}\text { Control } \\
\text { Group }\end{array}$ & Total & \\
\hline $\begin{array}{c}\text { Age } \\
\text { Mean-std } \\
\text { min-max } \\
\text { EP }\end{array}$ & $\begin{array}{c}63,00 \pm 9,31 \\
54-77 \\
2,80\end{array}$ & $\begin{array}{c}69,67 \pm 5,01 \\
65-76 \\
2.04\end{array}$ & $\begin{array}{c}68,50 \pm 10,67 \\
55-87 \\
435\end{array}$ & $\begin{array}{c}66,17 \pm 8,98 \\
54-87 \\
187\end{array}$ & 0,27 \\
\hline $\begin{array}{c}\text { Gender } \\
\mathrm{F} \\
\mathrm{M}\end{array}$ & $\begin{array}{cc}\mathbf{n} & \% \\
5 & 45,5 \% \\
6 & 54,5 \%\end{array}$ & $\begin{array}{cc}\mathrm{n} & \% \\
1 & 16,7 \% \\
5 & 83\end{array}$ & $\begin{array}{cc}\mathrm{n} & \% \\
1 & 16,7 \% \\
5 & 83\end{array}$ & $\begin{array}{c}7(30,4 \%) \\
16(6960)\end{array}$ & 0,32 \\
\hline $\begin{array}{c}\text { Years in PI } \\
\text { Median } \\
\text { min-max }\end{array}$ & $\begin{array}{c}5,00 \\
02-18 \\
\end{array}$ & $\begin{array}{c}3,00 \\
02-15 \\
02\end{array}$ & $\begin{array}{c}5,50 \\
02-20 \\
\end{array}$ & & 0,36 \\
\hline
\end{tabular}

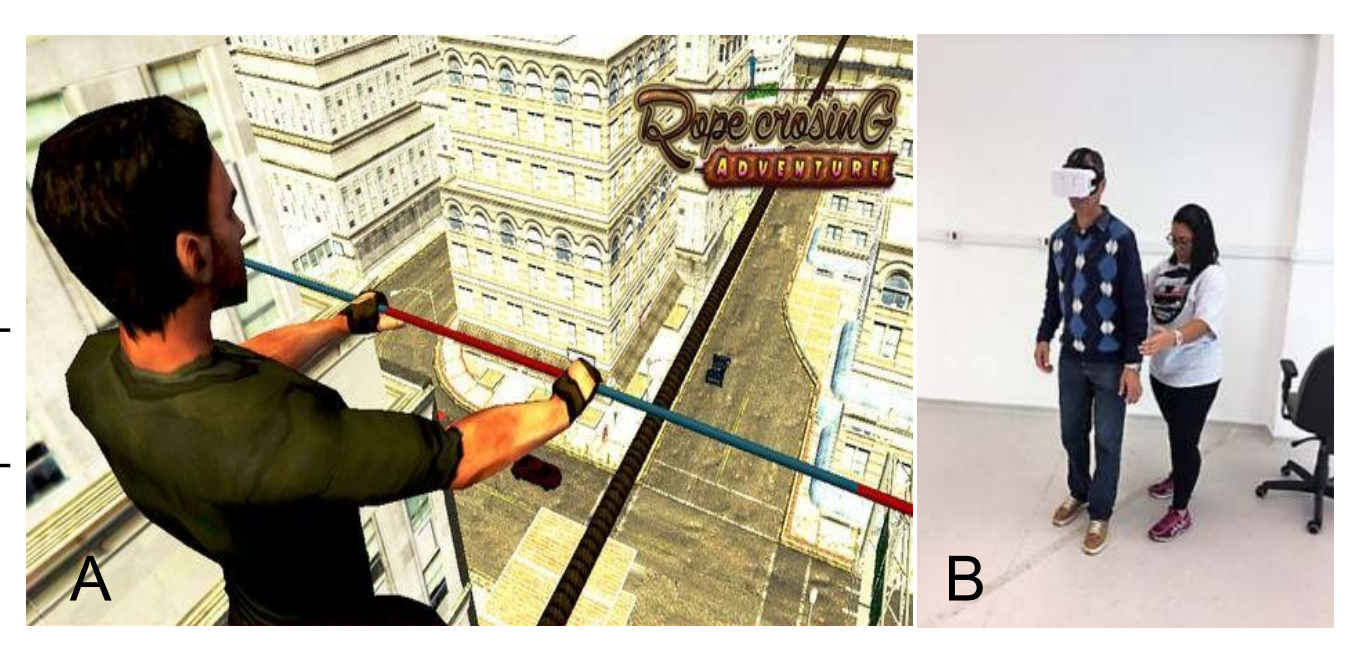

Fig. A: Sample of the tight rope IRV app (Rope Crossing Adventuree).

Fig. A: Sample of the tight rope IRV app (Rope Crossing Adventure@).
Fig. B: Patient performing the IRV protocol under a physical therapist supervision.

DISCUSSION

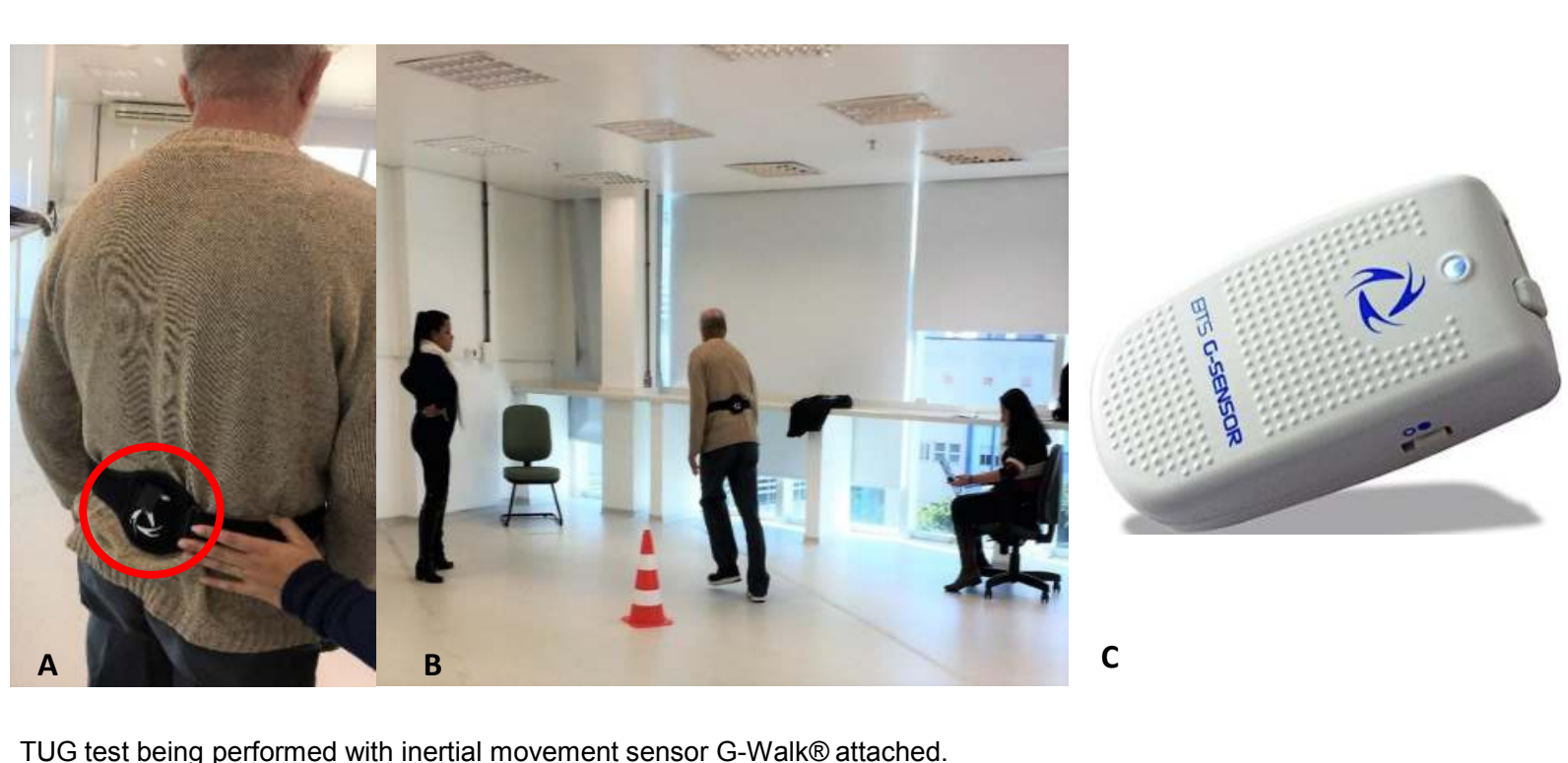

TUG test heing performed with inetrial movement sensor G-Walk@ attached.

Copyright $\odot 2019$ Oliveira, A.; Jaén, M.; Silva, D. E-mail: alcyr@ufcspa.edu.br
The results showed that PD patients submitted to a balance training in IVR might improve the motor feedback control. The results did not show cognitive changes which could be explained by the short period of time training. It is well reported that psychological effects are usually seen in longer treatments. However, the motor changes are insightful Although it has been pointed in only two measurements, these are the golden standard for PD evaluation. Considering that Parkinson's disease is a complex condition, it is advisable to increase the sample size in future studies. 